Entrevista 



\section{Duas imagens de Hernán Cortés: uma conversa com Christian Duverger}

Por Maria Emília Granduque José

Resumo: O historiador, antropólogo e arqueólogo francês Christian Duverger - diretor de estudos da École des Hautes Études en Sciences Sociales (EHESS Paris) e professor titular de antropologia social e cultural da Meso-América comenta, na entrevista que segue, os principais pontos levantados por seu mais novo trabalho Cortès et son double: enquête sur une mystification. Motivo de debate entre muitos historiadores da área desde sua publicação, em 2013, o livro perturba ao questionar a autoria da Historia verdadera de la conquista de Nueva España, até então atribuída ao soldado espanhol Bernal Díaz del Castillo. Nas 310 páginas da obra, dividida em duas partes (Os contornos de um enigma e $A$ resolução de um mistério) Duverger conclui, por fim, ser o próprio conquistador Hernán Cortés o autor de tal Historia, no momento em que está impedido pela coroa espanhola de escrever e publicar suas memórias.

Palavras-chave: Conquista espanhola. Século XVI. Bernal Díaz del Castillo. Hernán Cortés. México. Christian Duverger.

Por anos, historiadores e estudiosos reconheceram Bernal Díaz como autor da Historia verdadera de la conquista de Nueva España, obra mestra sobre a conquista espanhola do México. O que era uma crença certa para os pesquisadores da área de América e, sobretudo, para aqueles que estiveram envolvidos com a tradução, organização e edição da obra, foi posto em dúvida pelo trabalho Cortès et son double: enquête sur une mystification, do renomado historiador francês Christian Duverger. A partir de orientações como a do notável Lucien Febvre de que "[...] o historiador não é aquele que sabe. É aquele que procura. E, portanto, que repõe em discussão as soluções estabelecidas, que revisa, quando é preciso os velhos

Anos 90, Porto Alegre, v. 21, n. 40, p. 535-549, dez. 2014 
processos", ${ }^{1}$ Duverger examina os documentos para investigar quem é o autor da Historia verdadera... e reescrever mais uma nova trama dessa história.

Especialista em história da Meso-América, tema para o qual vem se dedicando com rigor desde seus estudos na Université de Paris IV-Sorbonne, onde defendeu a tese L'eprit du jeu chez les aztèques, orientado pelo também célebre historiador francês Jacques Soustelle, Duverger tem contribuído com importantes trabalhos sobre o universo meso-americano e a conquista espanhola do México. Dentre os principais livros publicados durante a sua trajetória acadêmica que expressam claramente a sua postura teórica vinculada à École des Hautes Études en Sciences Sociales (EHESS) - está La fleur létale, de 1979, obra que explica a cultura asteca por meio de seus ritos religiosos. Nesse interessante estudo, Duverger rompe com a visão clássica, acostumada a minimizar ou negar o sacrifício praticado pelos indígenas para mostrar que tal culto pode ser a chave de entendimento do mundo meso-americano. Já em La conversion des indiens de Nouvelle-Espagne, publicado em 1987, discorre sobre a introdução do cristianismo na Nova Espanha a partir da chegada dos primeiros missioneiros franciscanos. Nesse livro, explica que o processo de cristianização dos índios ocorreu de forma rápida e exitosa pela ação dos religiosos em adaptar o catolicismo aos ritos nativos por ordem do próprio Cortés. Mas é nas obras La Méso-Amerique, de 1999, e Elprimer mestizaje, de 2007, que Duverger concilia com mais veemência a sua formação antropológica e arqueológica, junto ao ofício de historiador, para lançar a tese de que a Meso-América nasce do encontro de povos sedentários - agricultores que viviam nessa região a partir de 1200 a.C - e povos nômades, que ele declara ser os nahuas. Com base em sua análise histórica filiada à longa duração, considera que a chegada dos espanhóis faz parte desse percurso iniciado antes por outros povos. Assim, na biografia Cortés, publicada, em 2003, já havia apresentado esse personagem como um novo tlatoani, ou seja, o substituto de Montezuma que conquistou a Meso-América e preservou o mundo asteca em transformação através da mestiçagem.

Durante esses longos anos debruçado sobre os mais variados documentos da época, para compor tal biografia, Duverger 
deparou-se com alguns fatos obscuros da vida de Cortés - como os anos finais passados em Valladolid e não documentados por nenhuma crônica - que lhe abriram caminho para uma investigação mais profunda sobre o conquistador. A tese formulada em Cortés et son double, livro impresso, em 2013, na França e no México, seguido de uma publicação na Espanha, nesse mesmo ano, trata de mostrar aos historiadores que Cortés esteve envolvido, no final de sua vida, com a escrita oculta de uma obra dedicada a contar a história da conquista espanhola no México. A obra em questão é nada mais do que a própria Historia verdadera de la conquista de Nueva España, então atribuída ao soldado espanhol Bernal Díaz del Castillo. Considerando que Cortés estava proibido por cédula real de escrever e que suas Cartas de Relación, publicadas, entre 1519 e 1526, deixaram de circular após serem censuradas, Duverger sugere que o conquistador criou um narrador fictício, aos moldes de um soldado anônimo que supostamente fez parte do grupo espanhol que esteve nas Índias, com o intuito de deixar registrado a memória de seus feitos empreendidos no México.

Sobre essa surpreendente revelação que tem chamado a atenção de muitos pesquisadores da área, sobretudo daqueles que resistem em desvincular a figura de Bernal Díaz com a autoria da Historia verdadera..., o próprio autor fala nessa esclarecedora entrevista sobre o livro Cortès et son double: enquête sur une mystification, concedida no dia 21 de janeiro de 2014.

M. E. No livro Cortès et son double, você escreve que os muitos indícios que resultaram na dúvida sobre a identidade do autor da Historia verdadera de la conquista de Nueva España passaram despercebidos pelos olhos de historiadores e estudiosos do assunto por todo esse tempo, como as incongruências a respeito da vida de Bernal Diaz del Castillo e do próprio Hernán Cortés. Se esses dois personagens são tão visitados na historiografia sobre América, não é estranho que ninguém nunca tenha investigado tais incongruências?

C. D. Nós nos acostumamos a pensar como sempre, como os historiadores do século XIX pensaram. Essa familiaridade impede o espírito crítico, que é um elemento importante. Então, para mim, o historiador deve acabar com esse sentimento de familiaridade, de 
Duas imagens de Hernán Cortés: uma conversa...

proximidade com esses autores conhecidos como Bernal Díaz del Castillo e Hernán Cortés e entrar em uma verdadeira pesquisa, que foi precisamente meu caminho.

M. E. A bistória conta que uma das grandes queixas do soldado Bernal Diaz del Castillo é que a Historia de la conquista de México, escrita pelo clérigo Francisco López de Gómora, não é confiável, pela condição ausente de seu autor. Tal como Bernal Díaz, muitos outros cronistas desse período valorizavam o testemunho de vista e a história escrita por que observou de perto os acontecimentos narrados, como Gonzalo Fernández de Oviedo, Pedro Cieza de León e Agustín de Zárate, para ficarmos em uns poucos nomes. Qual a sua opinião sobre essa questão colocada por esses cronistas de que a verdade era assegurada muito mais por quem viu os eventos e menos por aqueles que somente os escutaram?

C. D. Não sei se a noção de verdade é um tema levado em conta pelos historiadores da época. Acredito que a história sempre é uma aproximação de fatos, normalmente é uma apresentação dos fatos que dá sentido a uma ação humana. Há uma citação de Antonio de Guevara ${ }^{2}$ no início do meu livro, que eu acredito que era uma questão filosófica. Mas não sei se houve entre os historiadores da época, que são os cronistas, uma preocupação ao redor do tema da verdade, então essa ideia de que Cortés considera o tema de maneira concreta, construindo uma oposição entre os testemunhos oculares e os historiadrores de gabiente, é muito novo, porque normalmente os cronistas fazem uma espécie de síntese ou trabalho de compilação de documentos. Por exemplo, Gonzalo Fernández de Oviedo ${ }^{3}$, que é um cronista muito importante, não sei se se preocupa realmente em buscar a verdade. O fato é que quando ele diz que Pero Martír de Anglería ${ }^{4}$ não conheceu as Índias é uma maneira de valorizar seu próprio trabalho. Mas não sei se isso está em relação com a verdade ou em relação com a legitimidade requerida por Oviedo como cronista oficial, ou seja, como uma maneira de dizer que é especialista no assunto. De outra forma, considero que Cortés tem uma visão muito mais desenvolvida da problemática da história, atentando para duas maneiras de se fazer a história: através de testemunhos oculares ou através de documentos escritos. É uma espécie de oposição entre a oralidade e o escrito, que é muito interessante. Cortés construiu 
sua crônica, que ao final é dupla, através de Francisco López de Gómora, para ter a dimensão escrita e de arquivos e, em contrapartida, a dimensão ocular, que é a de Bernal Diaz del Castillo, que para mim é fruto absolutamente da pluma de Cortés. Isso, no entanto, é muito particular, normalmente, os testemunhos dizem "vou contar o que digo" e os historiadores dizem "o que encontrei nos arquivos foi isso", mas não colocam o problema da verdade; quem coloca é Cortés, para dissimular. Meu livro faz referência ao preâmbulo escrito por Gómora na sua Historia de la conquista de México, no qual não considera os testemunhos como historiadores porque, para ele, o historiador sabe investigar nos arquivos e ordenar as matérias, já os testemunhos oculares, somente contam suas histórias.

M. E. Você pensa que sua tese, ao contribuir com outro olhar para os estudos sobre Bernal Diaz e do próprio Cortés, pode mudar os rumos das pesquisas sobre América, ainda presas a certas figuras históricas intocáveis?

C. D. Sim, acredito que o livro muda o contexto em vários campos: em relação a Cortés, em relação a Bernal Díaz e, ainda, o que para mim é muito importante, em relação ao problema do controle da informação por Cortés. O que diz meu livro é que temos as Cartas de Relación escritas por Cortés, depois a versão produzida ao final de sua vida assinada pelo soldado Bernal Díaz, que é o duplo de Cortés, temos a história produzida por Gómora a partir da consulta dos arquivos de Cortés que ficavam na sua casa, em Valladolid, e temos uma quarta obra, a de Cervantes de Salazar ${ }^{5}$ - e meu livro explica de maneira bem clara que este autor frequentou a academia de Cortés e, depois da morte do conquistador, viajou para as Índias com o encargo de escrever uma crônica sobre a Nova Espanha. A respectiva crônica também se trata de um texto cortesiano, o que significa que citar Cervantes de Salazar para comprovar Bernal Díaz, para comprovar Gómora ou para comprovar Cortés, utiliza-se o mesmo ponto de partida, a mesma fonte. Nesse sentido, espero que meu livro possa induzir a uma investigação mais longa, diretamente voltada para os textos de arquivos, porque até o momento temos somente a versão de Cortés. Evidentemente, meu livro também muda a visão sobre Cortés, porque tudo o que explico a respeito de seus anos finais, de sua academia em Valladolid, de seu interesse pelo 
idioma e para os temas do Renascimento etc., é algo novo, que pode transformar a imagem construída até agora do conquistador como um soldado bruto. Quanto a Bernal Díaz, o que muda é um pouco mais psicológico, porque como nos acostumamos a considerá-lo o autor da Historia verdadera... há quem fique triste por perder essa figura. Então, eu vejo como uma espécie de ruptura sentimental, o que configura um outro tipo de mudança a respeito desse personagem. Acredito que é importante conhecer tudo isso para que uma nova geração de historiadores busque outros tipos de fontes, e não somente aquelas publicadas pelos cronistas de renome.

M. E. Ao final do livro, você sustenta que há um Cortés intelectualmente ativo e preocupado em deixar por escrito as suas memórias. A partir dessa ideia e com base nas considerações anteriores, você acredita que apareçam novas linhas de investigação sobre Cortés que aponte muito mais seu lado de escritor e homem de letras e não tanto de conquistador e homem de ação, como a bistoriografia tem produzido?

C. D. Sim, definitivamente, acredito que há muito mais textos e documentos que seriam de grande utilidade para completar o que sabemos desse momento muito interessante da conquista e dos primeiros anos dos espanhóis na América Latina. Há muitos documentos que estão em Sevilha, na Espanha, no México, na Europa - provavelmente em Viena haja outros documentos, pela relação de Cortés com o irmão de Carlos V -, na Itália, talvez, por causa do papado e dos contatos que tinha e, não podemos esquecer, que a metade da Itália era de Aragão e que certamente esses arquivos circularam. Por isso, acredito que sim, acredito realmente que há uma linha para os jovens, uma nova linha de pesquisa que pode ajudar muito a reescrever a história tão importante desse contato.

M. E. A tese central de seu livro Cortès et son double parte do questionamento sobre quem é o autor da Historia verdadera de la conquista de Nueva España. Depois de uma longa pesquisa, você conclui que todos os indícios recolbidos convergem para o nome do próprio Cortés, e não de Bernal 
Diaz. Se pensarmos no século XVI, vemos que a questão da autoria não era um problema colocado e que não havia uma preocupação com a originalidade do texto e de seu autor, como há atualmente. Como você compreende essa questão da autoria considerando a época em que viveu Cortés e Benal Diaz?

C. D. É uma pergunta interessante a questão da autoria. Havia inquietudes e dúvidas entre os historiadores, mas não se questionou profundamente a autoria de Bernal Díaz até a publicação do meu livro. Porque, finalmente, a mistificação foi bem feita, quando há mistificações mal feitas, as dúvidas são mais evidentes. Mas nesse caso foi muito bem feita, havia verdades sobre a história de Bernal Díaz. O que meu livro põe em evidência é que nem a melhor biografia colocou em dúvida essa questão, a historiografia aceitou Bernal Díaz como autor sem fazer uma investigação, sem apurar se realmente o personagem era capaz de ser o autor. O interessante é que os prefácios e os prólogos trazem sempre a mesma informação, que nunca são comprovadas, como uma espécie de repetição de dados. O que me chamou a atenção foi a ausência de uma biografia sobre Bernal Díaz, pois havia elementos de sua família. Mas relacionar a existência de um tal Bernal Díaz na Guatemala é uma coisa, dizer que ele é o autor da crônica é outra cosia. Então, o que nos faltava saber em primeiro lugar é se Bernal Díaz sabia escrever - e quanto a isso não temos prova nenhuma - e como ele pôde escrever uma história tão precisa quarenta anos depois dos fatos. Esse ponto que é preciso contestar e aí está a origem da minha pesquisa. Minha ideia é que a historiografia nunca nos deu uma prova capaz de relacionar Bernal Díaz à autoria da Historia verdadera... Por exemplo, temos duas ou três páginas sobre a vida de Bernal Díaz del Castillo nos prólogos que apresentam a obra, mas, na edição de Porrúa, que é uma edição popular do México, ainda utiliza um prólogo escrito em 1936. Por qual razão? Porque, provavelmente, os que tentaram fazê-lo desisitiram, por ser bastante difícil, preferindo, ao final, reutilizar esse prólogo já pronto, de 1936. Estamos em 2014 e até hoje as casas editoriais publicam um texto de Bernal Díaz, de 1936. Isso significa que sua biografia é impossivel, ou seja, é mais fácil repetir do que adentrar na obscuridade que envolve a sua vida. 
Duas imagens de Hernán Cortés: uma conversa...

M. E. Se o autor da Historia verdadera... é finalmente Cortés, até que ponto podemos compreender a trama construida por ele - a escrita oculta e a criação de um personagem - como uma atitude do homem do século XVI? Seria mesmo possivel que Cortés on qualquer outra figura dessa época fosse tão meticuloso para compor uma história assinada por um soldado inventado somente para ser lembrado pela posteridade?

C. D. Acredito que são duas perguntas em uma. No caso de Cortés, é particular, porque este conquistador é uma personalidade enorme, é um homem de grande importância na Espanha, é praticamente um competidor político de Carlos $\mathrm{V}$ e representa, no vocabulário de hoje, uma oposição política do rei. O que significa que é um republicano contrário à monarquia, contrário à inquisição, contráio à censura e ao sistema de monopólios que afeta absolutamente tudo. Devemos compreender o que era a Espanha da época, por exemplo, para se ter um barco, era preciso solicitar ao rei, para se ter uma terra, era preciso receber da coroa, para imprimir um livro, era necessário obter muitas autorizações, o que representa um sistema de controle muito estatizado, com muita censura. A tudo isso se opõe Cortés. Além disso, a sua personalidade e sua rica condição o tornavam um competidor político que atrapalhava Carlos $\mathrm{V}$ e, por isso, foi perseguido. Assim, no caso particular de Cortés, havia uma necessidade de recuperar um espaço de liberdade, de inventar um narrador anônimo. Por essa razão, decidiu criar a figura de um soldado raso para, talvez, evitar a possibilidade de ser identificado. Isso é um elemento importante e outro é que Cortés gostava de escrever, não era somente um homem de espada, mas um homem de pluma que entrou no jogo da escrita e da ficção (porque o narrador é fictício, ainda que os fatos sejam reais) próprio de sua personalidade. Contudo, isso não deve ser considerado como uma regra entre os cronistas da época, o caso de Cortés é único ao mesclar o elemento literário na história. Insisto que a necessidade de se esconder em um personagem fictício era lógico, em consequência das perseguições de Carlos V, o que não se passa com outros cronistas que eram favoráveis às ações da coroa. São dois elementos, um político e outro literário que, juntos, tornam esse caso excepcional. 
M. E. O jornal espanhol El País dedicou diversas páginas para tratar da publicação de seu livro Cortès et son double. Dentre os artigos escritos, há a crítica formulada por Guillermo Serés, catedrático da Universidad Autónoma de Barcelona. No texto El verdadero autor de la "Historia verdadera", rebate alguns pontos defendidos em seu livro, como la afirmação feita de que la Real Audiência não estava na Guatemala em 1568 e que Bernal Diaz não tinha conbecimentos de leitura e escrita fundamentais para fazer dele um autor. Vocêpensa que a desconstrução do mito Bernal Diaz, feita em sua tese, é o ponto de incômodo para os historiadores da América?

C. D. No caso de Guillermo Serés ${ }^{6}$, é preciso compreender que ele criticou sem ter lido meu livro. Vou dar alguns elementos: o livro saiu ao mesmo tempo na França, em francês; no México, em castelhano e, três meses depois, foi publicado na Espanha. O que ocorreu quando saiu o livro no México e na Espanha? $\mathrm{Na}$ Espanha, explico que o livro não circulava, não estava à disposição dos pesquisadores. No México, imediatamente, vimos que os historiadores profissionais, que nunca se deram conta do assunto, não aceitaram. Entendo perfeitamente isso, porque de uma certa maneira meu livro apresenta coisas que estavam à vista e que não foram percebidas por ninguém, justamente pelo costume e a familiaridade que temos com esse assunto. Então, isso provocou uma sensação de mal-estar e, além disso, meu livro mudou a visão de Cortés, fixada desde praticamente um século no México e mudou, evidentemente, a visão de Bernal Díaz del Castillo, que representava a possibilidade de um soldado raso ter escrito uma obra mestra da literatura mundial. Houve essa reação imediata. Mas, se compararmos com a França, o que passou? Toda a comunidade científica, todos os historiadores - porque temos na França especialistas nesse período - leram meu livro e foram visitar todas as referências e citações apresentadas por mim para saber se estava correto, bem feito, de acordo com as exigências históricas. E, durante dois meses, o livro não recebeu nenhum eco, o que me surpreendeu, porque eu pensei ter escrito um livro de uma certa importância. Mas a resposta viria dois meses depois da publicação, uma resposta crítica mas de aceitação, o que significa que depois de averiguarem tudo o que há 
em meu livro concordaram que não havia nenhum problema sobre a maioria dos pontos levantados. Evidentemente, quando utilizei as provas para eliminar a autoria de Bernal Díaz del Castillo, percebi que há provas que são de várias índoles, eu compreendo isso. $\mathrm{O}$ conjunto das provas finalmente é determinante. Mas, retomando as críticas, eu considero impossível que se fale do meu livro ser ter lido, porque é um livro de historiador sério, e não uma ideia solta. Acredito que as críticas são realmente uma primeira impressão de alguns historiadores que não se aprofundaram em nenhuma questão proposta por meu livro. Até agora, não recebi nenhuma crítica de fundo, de base sobre os elementos que ofereço. Muitas vezes, são detalhes que não são determinantes, como a questão já falada sobre a Real Audiência. O que me interessava nesse ponto é que estivemos em contato com a frase inicial da crônica por quatro séculos e ninguém fez uma averiguação para saber se era possível ou não. Dessa forma, era somente um exemplo para explicar e, aqui voltamos à sua primeira pergunta, para dar a entender que a utilização desses documentos de forma familiar acaba nos cegando e que, finalmente, a verdadeira pesquisa deve fazer perguntas a cada linha de cada documento, de modo que esse meu exemplo era nada mais do que uma demonstração de metodologia.

M. E. Falando um pouco mais sobre as criticas, o historiador mexicano Miguel León-Portilla remete-se à observação de Guillermo Serés para dizer, em um artigo publicado pela revista mexicana Nexus (01/04/2013) que seu livro apresenta uma fantasia excessiva por não sustentar nenhuma evidência concreta.

C. D. Eu aceitei a proposta da revista Nexus de apresentar as opiniões. Praticamente, quase todos que opinaram no volume de abril não leram o livro e opinaram com base em outras opiniões, o que não é o trabalho dos historiadores. E, ainda sobre o caso da Real Audiência a que se apegam esses estudiosos, quero dizer que esse não é o ponto central do meu livro e que sinto muito, mas León-Portilla ${ }^{7}$ equivoca-se. Isso significa que não há como fazer uma crítica sem ter lido o livro e feito as averiguações em seus devidos lugares. O interessante é que depois do volume de abril da revista Nexus, há 
uma resposta minha que explica o tipo de história que eu pratico e que tipo de história se pratica na École des Hautes Étudies de Paris, que é uma escola histórica dos Annales, que tem toda sua reputação e fama. $\mathrm{Na}$ resposta, eu explico como essa escola histórica integra os elementos ideológicos na pesquisa histórica, como que a tonalidade política do cronista é importante, assim como saber se ele recebeu do rei por ser simpático em seu relato ou se é um historiador da oposição. Todos esses elementos não são neutros, ou seja, são coisas que integramos. Mas preciso dizer que não escrevi o livro contra historiadores ou contra uma escola histórica em particular, é um livro que lidou somente com fontes e sem agressividade nenhuma. De todas as formas, o livro despertou um interesse muito grande no público em geral, então não posso considerar que as críticas de uma pequena parte de historiadores profissionais seja a única reação causada pelo meu livro. $\mathrm{Na}$ França, por exemplo, precisamente, o livro impulsionou uma certa novidade sobre o fazer história, sobre uma certa concepção de história que vai obrigar os historiadores a outro tipo de pesquisa.

M. E. Para encerrar nossa entrevista, gostaria que você falasse um pouco mais sobre suas referências teóricas. Em muitas obras, o historiador francês Paul Veyne sustenta que a bistória é nada mais do que uma narrativa dos fatos e que os acontecimentos têm sentido somente dentro de uma trama elaborada pelo bistoriador. Seu trabalho Cortés et son double está no caminho dessa mesma perspectiva histórica?

C. D. Conheço Paul Veyne ${ }^{8}$, que também foi da École des Hautes Étudies. Sim, estamos na mesma perspectiva histórica. A verdade é que a École des Hautes Étudies, que é a instituição científica a que pertenço, nos propõe trabalhar primeiro sobre a longa duração e depois incluir na história elementos que às vezes não estavam inclusos. Esse tipo de história considera que não podemos somente nos concentrar no papel dos atores da história, mas também nos contextos sociais. Por exemplo, há uma impossibilidade de Bernal Díaz ser letrado por razões estatísticas, ou seja, um elemento que eu considerei foi o nível de alfabetização da Espanha medieval. Isso é um dado social que não influencia diretamente sobre o conteúdo que escreveu Bernal Díaz, 
mas a verdade é que somente $1 \%$ ou até $2 \%$ da população sabia ler e escrever. Então, se considero essa porcentagem para a análise do exército de Cortés, vejo que na representação dos letrados desse grupo, composto por um notário e dois ou três religiosos, é muito difícil encontrar um soldado que soubesse ler e escrever, trata-se de uma excentricidade. Embora seja um exemplo, é um elemento que devemos considerar, aliás, devemos tomar os elementos que não sejam vinculados diretamente à atuação de Cortés, mas ao contexto social que, nesse caso específico, indicou-me que dos quinhentos membros da tropa espanhola não temos mais do que cinco ou seis letrados. Então, estou de acordo com Veyne, complemento que há uma construção na história feita pelos historiadores e que devemos desconstruí-la, considerando também porque se construiu assim o mito Bernal Díaz e a imagem de Cortés. O que significa que um historiador nunca está excluído de seu contexto social, político e religioso, operando com uma formação intelectual em um contexto dado, esse é o sentido da história que pratico.

\section{TWO IMAGES OF HERNÁN CORTÉS: A CONVERSATION WITH CHRISTIAN DUVERGER}

Abstract: The historian, anthropologist and archaeologist french Christian Duverger - director of studies at the École des Hautes Études en Sciences Sociales (EHESS-Paris) and professor of social and cultural anthropology of Mesoamerica - says, in the interview that follows, the main points raised by his newest work Cortès et son double: enquête sur une mystification. Subject of debate among many historians of the area since its publication, in 2013, the book disturbing to question the authorship of Historia verdadera de la Nueva España, then assigned to a spanish soldier Bernal Díaz del Castillo. In the 310 pages of the book, divided into two parts (The contours of a puzzle and Solving a mystery) Duverger concludes, finally, be the conquistador Hernán Cortés himself the author of this history the moment is prevented by the spanish crown write and publish his memoirs.

Keywords: Spanish conquest. Sixteenth century. Bernal Díaz del Castillo. Hernán Cortés. Mexico. Christian Duverger. 


\section{Notas}

${ }^{1}$ FEBVRE, Lucien. O problema da incredulidade no século XVI: A religião de Rabelais. São Paulo: Cia das letras, 2003. p. 29.

${ }^{2}$ Antonio de Guevara foi um cronista espanhol que viveu no século XVI. A citação referida por Duverger, presente na epígrafe de Cortès et son double, transcrevemos a seguir: "No ay cosa tan entera que no se desminuya; no ay cosa tan sana que no se estrague; no hay cosa tan rezia que no se quebrante; no ay cosa tan guardada que no se corrompa: todas estas cosas el tiempo las acaba y sepulta, sino a sola la verdade, la qual del tiempo y de todo lo que es en el tiempo triumpha". GUEVARA, Antonio de. Libro áureo de Marco Aurelio, 1528.

${ }^{3}$ Gonzalo Fernández de Oviedo foi um historiador e cronista espanhol que publicou, em 1526, seu Sumario de la natural historia de las Índias. Nomeado, em 1532, para o cargo de cronista oficial das Índias redigiu sua obra maior intitulada Historia general y natural de las Indias que teve a primeira parte publicada, em 1535, e a segunda, postumamente, em 1557.

${ }^{4}$ Pedro Mártir de Anglería foi um cronista oficial das Índias que escreveu, no final do século $\mathrm{XV}$, as primeiras descrições sobre a conquista espanhola da América Central. Fruto de sua posição, teve acesso a uma série de documentos e relatos que serviram, futuramente, como base para a escrita de suas Décadas del Nuevo Mundo, publicadas, em 1511, sendo a primeira edição completa, em 1530. Por nunca ter estado nas Índias e ter escrito sua crônica unicamente pela consulta de documentos, foi criticado por Gonzalo Fernández de Oviedo, que o considerou pouco fiável em suas afirmações.

${ }^{5}$ Francisco Cervantes de Salazar foi um cronista espanhol que esteve no México, em 1551. Dessa experiência em terras americanas, escreveu, dentre outras obras, a Crónica de la Nueva España, escrita entre 1557 e 1564. Como letrado, também foi um dos tradutores e comentaristas do humanista español Juan Luis Vives. Próximo de Cortés, Salazar pôde redigir sua obra a partir de informações fornecidas pelo próprio conquistador e pela consulta das cinco Cartas de Relación, além, claro, de sua percepção particular sobre o que presenciou no México.

${ }^{6}$ Guillermo Serés é catedrático na Universidad Autónoma de Barcelona, onde ministra aulas sobre Literatura espanhola. Publicou muitos trabalhos sobre a escrita medieval e o século de Ouro. Um de seus livros trata da Historia verdadera de la conquista de Nueva España e do soldado Bernal Díaz del Castillo, intitulado La conquista como épica colectiva: la obra de Bernal Diaz del Castillo, publicado em 2005. 
${ }^{7}$ Miguel León-Portilla é um historiador e antropólogo mexicano que centrou seus estudos sobre o pensamento e a cultura náhuatl. Dentre seus livros mais conhecidos estão sua tese de doutorado, publicada em 1956, com o título $L a$ filosofía nábuatl estudiada en sus fuentes, A visión de los vencidos (1959), Los antiguos mexicanos a través de suas crónicas y cantares (1961).

${ }^{8}$ Paul Veyne é um historiador francês que estuda antiguidade romana. Publicou diversos trabalhos sobre essa temática, como O pão e o circo (1976), Acreditaram os gregos nos seus mitos? (1983), Sexo e poder em Roma (2005), Quando nosso mundo se tornou cristão (2007) e outros em que trata mais especificamente da sua afinidade com o pensamento foucaultiano, presente em Como se escreve a história (1970) e Foucault: o pensamento, a pessoa (2008).

\section{Referências}

CERVANTES DE SALAZAR, Francisco. Crónica de la Nueva España. Madrid: Hispanic Society of America, 1914.

CORTÉS, Hernán. Cartas de Relación. Madrid: Dastin, 2003.

DÍAZ DEL CASTILLO, Bernal. Historia verdadera de la conquista de Nueva España. México: Editorial Porrúa, 2011.

DUVERGER, Christian. Cortès et son double: enquête sur une mystification. Paris: Seuil, 2013.

. L'eprit du jeu chez les aztèques. Paris: École des Hautes Études en Sciences Sociales, 1978. . La fleur létale. Paris: Seuil, 1979. . La conversion des indiens de Nouvelle-Espagne. Paris: Seuil, 1987. . La Méso-Amerique. Paris: Flammarion, 1999. . Cortés. México: Taurus, 2005. . Elprimer mestizaje. México: Taurus, 2007.

FEBVRE, Lucien. O problema da incredulidade no século XVI. A religião de Rabelais. São Paulo: Companhia das Letras, 2003.

FERNÁNDEZ DE OVIEDO, Gonzalo. Historia general y natural de las Indias. Madrid: Editorial Atlas, 1992. . Sumario de la natural historia de las Indias. México: FCE, 1996.

GUEVARA, Antonio de. Libro aureo de Marco Aurelio. Madrid: Turner, 1994. 


\section{Maria Emília Granduque José}

LEÓN PORTILLA, Miguel. Los antiguos mexicanos a través de sus crónicas y cantares. México: FCE, 1972. . La filosofía nábuatl estudiada en sus fuentes. México: UNAM, 1979. . La visión de los vencidos. México: UNAM, 2007.

LÓPEZ DE GÓMORA, Francisco. Historia de la conquista de Mexico. Venezuela: Ayacucho, 1979.

MARTÍR DE ANGLERÍA, Pedro. Décadas del Nuevo Mundo. Madrid: Ediciones Polifemo, 1989.

SERES, Guillermo. La conquista como épica colectiva: La obra de Bernal Díaz del castillo. Madrid: Ediciones Clásicas, 2005.

VEYNE, Paul. Le Pain et le Cirque. Paris: Seuil, 1976. . Como se escreve a história. Brasília: UNB, 2008. . Sexo e poder em Roma. Rio de Janeiro: Civilização brasileira, 2008. - Quando nosso mundo se tornou cristão. Rio de Janeiro: Civilização brasileira, 2011. . Foucault: o pensamento, a pessoa. Lisboa: Edições Texto \& Grafia, 2009. . Acreditaram os gregos nos seus mitos? Lisboa: Edições 70, 1983. 